\title{
Rapid Earthquake Alarm System and Real-Time Automated Action: Application of Multi-Agent Hardware
}

\author{
Ahmad Ghodselahi \\ $\mathrm{PhD}$, University of Tehran, Tehran, Iran (Corresponding author) \\ E-mail: Ahmad.Ghodselahi@gmail.com \\ Mostafa Ghodselahi and Farid Tondnevis \\ MSc, Allameh Tabatabaee University, Tehran, Iran, PhD Candidate, University of Tehran, Tehran, Iran \\ E-mail: mostafa.g.elahi@gmail.com, farid_ftnk@yahoo.com
}

Received: 22 October 2017; Accepted: 03 December 2017; Published: 08 February 2018

\begin{abstract}
Earthquake is the most dangerous natural disaster in the whole era of human being life. Scientist efforts for predicting earthquake have no prolific result, so far. The earth complexity and geology structures are the main obstacles of these efforts. The importance of time at the occurrence of the earthquake has resulted in using powerful systems for real-time alarming and therefore lessening the casualties of the earthquake. In this paper we have designed a rapid earthquake alarm system and we have implemented it in parallel processing and continuous processing. We have tried to apply hardware intelligent agents for real-time and parallel processing of data and data fusion of sensors. By applying this technology, the performance of rapid earthquake alarm system will be improved. Through this improvement, the rapid and automated action of rapid earthquake alarm system can lead to reducing the effect of earthquake.
\end{abstract}

Index Terms-Multi-agent Hardware Precursor, earthquake Rapid Reaction.

\section{INTRODUCTION}

Earthquake is the shaking of earth, which is the reason of rapid release of energy and often is due to fault slippage. The released energy from its source, which is named focus, is disseminated in all aspect. These waves is similar to waves generated from apiece stone fallen into water. Alike the waves in the water, the waves of earthquake will disseminate in the surface of the earth. As the waves outspread from the focus rapidly, some sensitive devices around the world will sense these waves and record them [1]. Earthquakes are categorized in different group according to their characteristics. Different types of earthquakes are:

1. Tectonic earthquakes: Many of the earthquakes occurring in the world yearly are tectonic earthquake. The movement of tablets, which is the former of earth cortex, is the reason of this type of earthquake.

2. Volcanic earthquakes: these kinds of earthquake occur in the places with volcanic mountain and are referred volcanic explosion, too.

3. Collapse earthquakes: the collapse of caves and underground channel can cause shakes named Collapse earthquakes.

4. Induced earthquakes: As the reason of abrupt changes in sluices, these kinds of earthquake occur.

5. Explosions earthquakes: The military of industrial explosions is the main cause of these earthquakes. The magnitude, place and the time of occurrence are predictable.

Measuring the earthquake is based on two approaches. One is based on device measurement and the other on is based on the influences that earthquake has on handiwork [2]. The intensity of earthquake is different in various places and will reduce by diffusing farther from focus, but the magnitude of earthquake is constant and is not dependent to the distance from focus, because it is directly pertain to the total released energy.

\section{A. Earthquake magnitude}

Earthquakes magnitude is used in order to measure earthquakes and obtain an evaluation criterion, which is in accordance to the range of fluctuation [3].

\section{B. Seismology}

It has been centuries that scientists are researching about earthquakes. Nowadays great networks of seismographs are installed all around the world and are registering different quakes. These data make the feasibility of earthquakes research. When earthquake occurs, different waves will be generated each of which has various speed and range. By having different speed, the reach time of these waves to seismograph is different. The focus and depth of earthquake is calculated based on 
the differences in the reach time of $\mathrm{P}$ and $\mathrm{S}$ waves. The drastic movement of the earth is the main cause for ruination of handiwork and people damages. Generally, after earthquake occurrence and earth energy release, the released energy disseminated as quakes waves in all dimensions and transmits the energy with them. Earthquake wave are categorizes into two groups based on their movement in or on the surface of the earth. These two groups are body waves and surface waves. Body waves move and convey in the body of earth and are transmitted in all dimensions and are faster than surface waves. Body wave is also categorizes into two kinds of waves, namely, primary waves and secondary waves. Surface waves have the most energy causes from low-depth shakes and are the main reason of residential areas damages. Surface waves have two kinds of waves, love waves and Rayleigh waves. Aforementioned waves are differentiated base on their speed, range, wavelength, alternation and frequency.

- Primary waves: Primary waves are capable of passing from different environment e.g. gases, solid and liquid environments. Ingredients that are exposed to this kind of waves are fluctuating forward and backward. The name of primary waves is generated from their speed, for they are the first waves sensed by seismographs. They lose their energy as transmitted and cause almost no damage.

- Secondary waves: These kinds of waves are transmitted in such environment that can resist against transfiguration e.g. solids. These waves cannot pass through gases and liquid environments. The fluctuation is staple.

- Rayleigh waves: These kinds of waves have circular movement like the movement of waves in an ocean. But the direction of movement is contrary to ocean waves.

- Love waves: The movement of these waves is similar to secondary waves. But the direction is parallel to the earth surface.

\section{Focus and depth of earthquakes}

The location of rupture in the fault is called earthquake focus or hypocenter and it is the primary place of energy release inside of the earth. Earthquakes are grouped into three classes based on their depth:

- Low depth: with the depth of 0 to $70 \mathrm{KM}$.

- Mediate depth: with the depth of 70 to $300 \mathrm{KM}$.

- Deep: with the depth of more than 300 KM (No earthquakes have been occurred with the depth of more than $720 \mathrm{KM}$ ).

The depth of earthquake is important matter because the intensity of damage and the region exposed to quake damage are related to its depth.

\section{CONCEPTS \& RELATED WORKS}

\section{A. Earthquake prediction}

Earthquake prediction is the prediction of time, location and the magnitude of a quake, which is forthcoming. Nowadays the location of quake is predictable to somehow but the time and magnitude of it is not accurately predictable. One of the ways for predicting the earthquake is to trace the precursor of quakes. Earthquake occurrence has some precursor, which occur before quakes. These precursors can be e.g. magnetic scopes, electrical scopes, shaking behaviors, atmospheric incidents and so on. Many precursors occur before earthquake occurrence, but none of them can definitely be an earthquake occurrence criterion, alone. Although many researches have been done in this field, it is not clearly defined whether or not a generic pattern for earthquake occurrence exists. In spite of the mentioned issue, for predicting earthquake occurrence some prerequisite are needed which are as follow:

- Short quakes reduction: seismographs are recording the generated quakes ceaselessly. The reason of quakes reduction is stone volume increase before rupture, which leads to cracks in stone. This phenomenon causes quake reduction and changes the transmitting speed [4].

- Crust deformation: the reason of most of major earthquakes is sudden break in the part of the crust, which hinder the movement of plate of the crust. By applying tension on plate of the crust, deformation occurs on some definite location of earth $[5,6]$.

- Change in the level of well water: This incident occurs because of the temperature changes and pressure decrease or increase on soil holes which make the water level to spurt or shrivel.

- Increase in the distance of earth near the location of rupture and fault: these changes are captures through accurate measuring devices and aerial photography [7].

- Earth temperature changes and gases emersion: the changes in the temperature of the earth and gas emersion such radon and argon that make the animals to come out from their nest in the earth. Investigation of geochemical gases especially radon is one of five main earthquake precursor introduced by International Institute of Seismology and earth science physic [8,9]

- Earth electromagnetic changes: changes in earth characteristic like electromagnetic [10].

- Animal behavior: animals show various behaviors before earthquake, e.g. fishes come seashore.

Regarding the importance of earthquakes and its prediction for saving people lives; researchers have investigated some methods for earthquake prediction. Novikova and Rotwain [11] applied CN algorithm for prediction of earthquake in 22 regions. In 11 cases from 24 cases, the alarm was at right time, earthquake 
occurrence time. Vorobieva [12] investigated an algorithm for the prediction of a subsequent large earthquake, which is based on analysis of the aftershock sequence following the first shock and of local seismic activity preceding it. He had considered that many large earthquakes come in pairs separated by relatively small times and distance. Murru and Console [13] utilized an earthquake clustering epidemic model for short-term forecasting of mediate and major earthquake. They consider every earthquake as being started by previous event and starting subsequent earthquakes. The model predicts the magnitude and probability of shaking in upcoming 24 hours. Uyeda et al. [10] applied the methodology of reverse tracing and monitoring precursor for short time prediction. Pulinets [14] applied spacecrafts for monitoring precursors and subsequently, short time prediction of earthquakes. Talebian et al. [15] investigated the electromagnetic change as a precursor of earthquake and by monitoring such changes; it was revealed that electromagnetic anomaly lead to earthquakes. Resaneh and Hajbabaee [16] investigated temperature anomaly, temporary temperature increase, almost 1 week prior to earthquake as a precursor of it, which can be captured from satellite. Ondoh [17] tried to predict earthquake based on ionosphere, atmosphere and water level as earthquake precursors. Nanjo et al. [18] proposed a modification of pattern informatics method, which has been designed for predicting the location of forthcoming major earthquakes and is based on analyzing the space-time patterns of past earthquakes to find possible locations where forthcoming earthquakes are exposed to occur. In this modified method the effects of errors in the location of past earthquakes on the output predict are reduced. Their goal is to more accurately define the location of forthcoming earthquake. Adeli and Pankat [19] designed an artificial neural network for predicting major earthquakes magnitude in future. The prediction is based on 8 parameters as earthquake indexes. Alcik et al. [20] established an early warning system that applied a simple and robust algorithm, based on the exceedance of specified threshold time domain amplitude and the cumulative absolute velocity levels. Manjunatha et al. [21] developed a $n$ automated system for fire detection for manufacturing industries. They have used neuro-fuzzy algorithm to identify the exact location of fire pixel in the image frame. Hepsiba and Justus [22] defined the important role of data and knowledge and the process of knowledge creation. The carried a survey on the knowledge representation models. Hazra et al. [23] addresses a number of target searching problems related to various defense scenarios by considering mobile sensors.

\section{B. Multi agent system}

Application of multi agent systems have been considered in many field, such as social science, engineering [24], physical theories and mathematics. Multi agent systems are a subfield of distributed artificial intelligence, which have attracted so many concentrations toward it. Rapid evolution and improvement in computer resources, both hardware and software, that are in use in computational and distributed environments, has lead to this growth. Agent technology is base on reactive, autonomous and active entities that evolves in dynamic environment [25]. Agent has a collection of goals, definite capabilities for functioning, and set of beliefs and knowledge about its environment. Agent would use its knowledge for reasoning in its environment so that perform its operations and reaches to its goals. The multi agent system paradigm is a popular and effective method for building a co-operating knowledge base team with same goal. A multi agent system consists of a group of agents, interacting with one another to collectively achieve their goals. By drawing on other agent's knowledge and capabilities, agents overcome their inherent bounds of intelligence [26]. Multi agent systems' models have fine representation of entities, which are distributed, functionally and geographically. The architecture of multi agent system is dynamic and has following characteristic:

The structure of agents is dynamic. The role of agent is defined through its services presenting in multi agent system. Once the role of agent is changed, the agent should present the services related to its new role and the structure of system should adapt with this alteration.

The structure of communication between agents is dynamic: The agents that a specified agent is connected to them and has communication with them would change in different period of agent lifetime base on the operation it is performing.

Agent-based techniques are from an attractive paradigm for building real-time parallel applications because they have several high-level characteristics: flexibility, modularity, concurrency, reactivity, proactiveness, reasoning, learning, autonomy, communication, and cooperation. When agents are effectively implemented, they can react to environmental changes by adapting to unpredictable events [27]. Having specifications like scalability, flexibility, reliability and robustness, multi agent systems can perform their parallel operation, which bring more speed and efficiency rather than centralized systems. Multi agent systems take a distributed problem solving approach where the agents are autonomous and socially situated, and can react to a dynamically changing environment [28]. Multi agent systems allow the simulation of complex phenomena that cannot easily be described analytically. Multi agent approaches are often based on coordinating agents whose actions and interactions are related to the emergence of the phenomenon to be simulated [29]. Agents have traditionally been assumed to be constructed using computer software. However with the advent of large-scale commercially available reprogrammable logic, it is now possible to extend the multi agent paradigm to a more general environment in which agents can reside in both the software and hardware of the system. The current state of Field Programmable Gate Array, FPGA technology and other reconfigurable hardware has allowed hardware to be much more flexible, and in so doing has narrowed the 
gap between hardware and software [30]. One application of hardware agent is in automated sensors field. Network of sensors is needed for utilizing many of sensors in order to gather information from different locations. This kind of network consists of sensors, which have connection with each other wirelessly. These sensors are applicable for environments that are not easily reachable [31]. Most of automated systems have sensors for information gathering and awareness of their environmental condition. The system uses this information as feedback for controlling modules. The capability of a system for performing a task is nearly dependent to the information quality received from sensors, which is pertaining to sensor quality. Data fusion is done for resolving this kind of deficiencies and this is possible from combining the information of two or more sensors. FPGA technology and other reconfigurable hardware technologies make it possible for hardware implementation, which brings more flexibility rather than the flexibility generated by software. Implementation of agent-based techniques in reconfigurable hardware makes it possible to build real time systems that predispose more parallelism rather than software systems. To be effective, hardware agent based systems must continuously adapt their behavior to meet the temporal demands of the run time environment. To accomplish this, agents can be implemented in a wide variety of ways that allow their belief systems to evolve over time in direct response to various forms of learning stimuli that come from the environment and interaction with other agents in the system. Naji et al. [28] presented data fusion through hardware agents for taking advantage from the advantage of hardware agents and their ability. It is obvious that application of some sensors could decline the uncertainty and supply more accurate information rather than a single sensor. The aim of sensor network application is to provide robust and reliable evaluation.

\section{RESEARCH MODEL}

In order to build a real time earthquake alarm system we need following issues:

- Earthquake network infrastructure

- Real time incident identifier

- Estimation of earthquake damage

- An alarm system

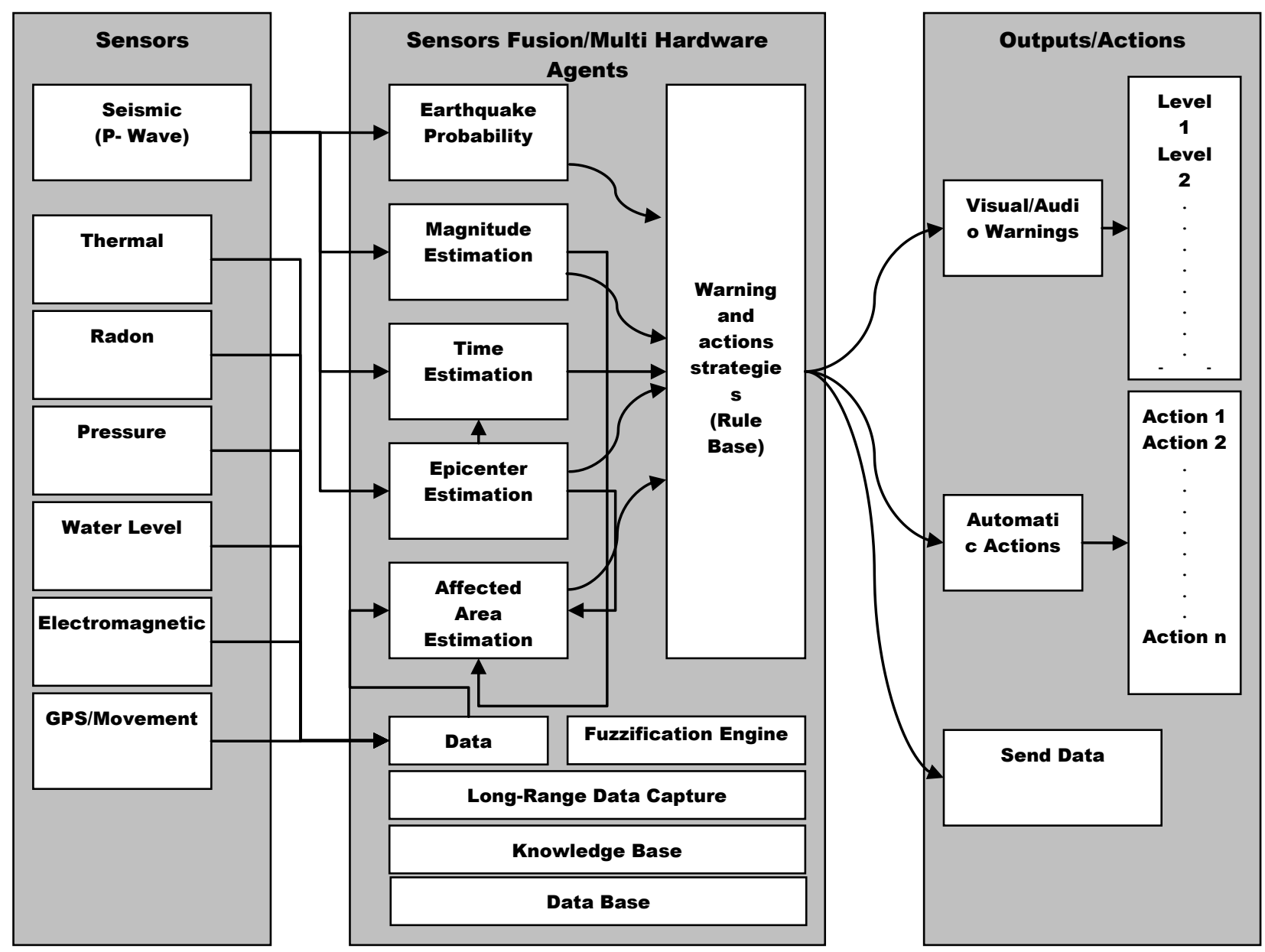

Fig.1. Proposed model 
It is important to note that current technology limit the hardware agent to have less complexity in structure and more reliability in operation than software agents. In order to facilitate their implementation, as hardware agents within reprogrammable logic, the sets of beliefs, desires and intentions may be reduced to the minimum set necessary to provide adequate though sometimes suboptimal understanding and control of the system [27]. Earthquake identifier and real time alarm systems are in need of rapidity and maximum productivity from earthquake time occurrence. For installing sensors and earthquake identifier processors in the unhandy location and highland, the energy resource supplement is an important matter. Another potential advantage of hardware agent is lower power consumption. Hardware agents can be better suited for monitoring the environment and placing different system elements into low-power standby mode, which more efficiently reduces power consumption. Also implementing a system entirely in reconfigurable hardware might use less power than one using microprocessors because reconfigurable hardware will implement only the necessary functions at any one time. In contrast, microprocessors typically implement more instructions than are normally used, particularly when using a complex-instruction-set computing processor rather than a reduced-instruction-set computing processor [27].

\section{IMPLEMENTATION AND TEST OF MODEL}

If designers use a multi agent system to perform several operations in a complex computational system, they can implement each operation or each group of operations with a single agent. The agents act in parallel on isolated operations, get information from the environment or other agent agents, and send the results back to the environment or other agents. Implementing the operations with hardware agent exploits the specialized hardware's speed in processing the input information and producing the results. Whenever each agent completes the operation, it sets its "done" signal and sends it to the successive agent's "strobe" signal. Then it sends the value of that result to the agent in the next level. In this model, hardware agents use done and strobe signals for handshaking. Agents can use their request and acknowledge signals to interact with the environment. Each agent is nondeterministic and intelligent. It receives input information and saves its current state in memory. Its new state is a combination of the old state, what it has learned from the environment, and what it has calculated itself. If an agent doesn't receive any information within a certain period of time, it will timeout and take appropriate action relative to the environment and according to its current state. For earthquake prediction or earthquake early warning accurate and real-time information gathering and information processing for calculating the earthquake time is an important issue. Therefore, it is proposed that a network of seismographs and measuring sensors stations for monitoring and recording the earthquake precursors measurement, like temperature, pressure, level of radon, level of water and electromagnetic, be utilized. In order to reduce any delay, each station consists of set of processing systems and hybridizing of hardware and software agent, which perform the information processing rapidly and autonomously. Application of intelligent hardware agents considering their advantages in speed, reliability, efficiency, low energy consumption and aforementioned advantages is rational in earthquake rapid alarm system [32, 28, and 27]. Regarding the importance of any fraction of time, application of hardware agent makes us capable of using any split of time [33,34]. Each station must send the captured information in definite period of time to an integrated database and this database should be maintained. Data mining will be performed on the information of the database for discovering the earthquake occurrence pattern and the relation of each precursor with the earthquake occurrence. Beside this database, by using expert knowledge in terms of discovered pattern from the information of database, extracting unknown pattern and related data will be possible gradually. So, we will have a growing knowledge base that will compare the recognized pattern with new information received from different stations and any miss accordance will be investigated. There will be a cloud of information between different stations that any valuable information and recognized pattern will be circulated in all stations. For saving any time and reducing delay for early warning of earthquake protocol will be used for information dissemination between all stations in same time instead of peer-to-peer protocol. In each station an agent is responsible for receiving other stations information and transmition of this information to other agent or activating other agent. For instance, when a high possibility of earthquake and its estimated magnitude is received from other station, the responsible agent role is to activate the agent which can estimate the magnitude of earthquake at the location of its own station providing that earthquake occurs. These station agents also transmit the processed information to other stations. One important part of each station is its sensors. These sensors should be active permanently and be standby to capture the shakes, while should define fake shakes. The state chart of stations' sensors is presented in figure 2 . Earthquake detection is possible through three ways:

- By receiving primary shakes of earthquake via each station's sensors.

- By receiving the information of precursor and utilization of knowledgebase and expert system or data mining for predicting the probable upcoming earthquake.

- By receiving the processed information relating to earthquake occurrence from other stations.

Once each station received the earthquake signals, it embarks on computing the impact and possibility of earthquake on its own related area and performs the strategies associated with the earthquake impact and 
possibility. If needed, the station will perform preventive actions. The formalism used for the hardware agents is derived from the well-known Beliefs, Desires, and Intentions (BDI) architecture. In the beliefs, desires, and Intentions architecture each agent maintains a set of beliefs, a set of desires and a set of intentions. The set of beliefs indicates what the agent currently believes to be true concerning its environment. It is a localized view where what an agent believes to be true may or may not in fact be true. For a system as a whole the set of desires is a set of outcomes that each agent would like to cause in its own environment. Note that the agent may or may not be able to bring its desires about. Achieving its desire may require action from other agents or may not be possible at all. Finally, the set of intentions is a set of actions that the agent intends to take to attempt to bring about its desires. The agent includes a function to map its inputs and current set of beliefs to an updated set of beliefs. Also, the agent has a function to map its current set of beliefs to a set of desires. Finally, the agent has a function that maps its set of desires to the set of intentions that are to be invoked to bring about these desires [28, 35].

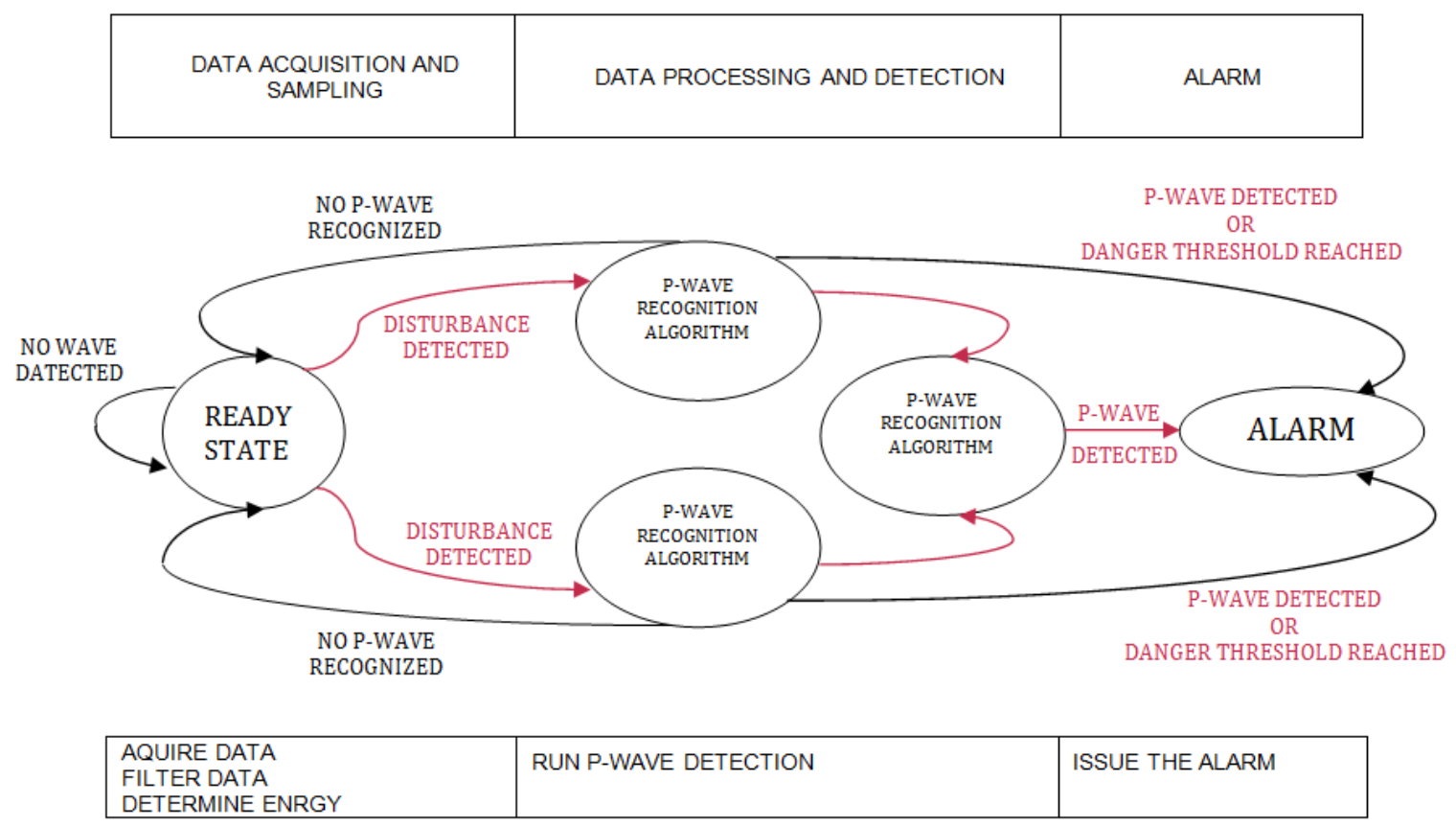

Fig.2. State chart of station seismograph

In the tables 1 through 5 some relationship for earthquake prediction and its precursor are presented in the BDI architecture. In proposed model sets of sensors and agents are utilized. Sensors are for monitoring the precursor changes. As it was mentioned in previous sections, before the earthquake occurrence or as it occurs, different events and changes take place. Different earthquake may have different or similar precursors. Monitoring one precursor is not sufficient for earthquake prediction. On the other hand monitoring all precursor changes is not possible due to difficulty in implementation and making apt infrastructures. In the proposed model some common precursors, which have taken, place in the most past earthquakes are considered.

Table 1. Earthquake Magnitude Estimation Agent

\begin{tabular}{|c|c|c|c|c|}
\hline Bel & & & & Intentions \\
\hline $\begin{array}{l}\text { a) } \\
\text { b) } \\
\text { c) } \\
\text { d) } \\
\text { e) } \\
\text { f) }\end{array}$ & $\begin{array}{l}\text { Location }(X, Y, Z) \\
\text { Time } \\
\text { xi : the ground motion recorded at time i } \\
\alpha: \text { a } 1 \text { sec smoothing constant (for } 100 \text { sps data } \alpha=0.99 \text {, for } 20 \text { sps data } \\
\alpha=0.95) \text {. } \\
\text { Xi: the smoothed ground velocity squared } \\
\text { Di: the smoothed velocity derivative squared }\end{array}$ & & $\begin{array}{l}\text { Earthquake } \\
\text { Magnitude }\end{array}$ & 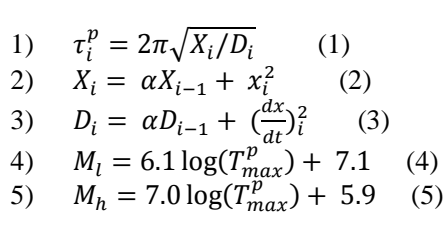 \\
\hline
\end{tabular}

With the closest station, the average absolute error in the magnitude estimate is 0.70 but when the closest 10 stations are used, the average error drops to 0.35 
Table 2. Earthquake Probability Estimation Agent

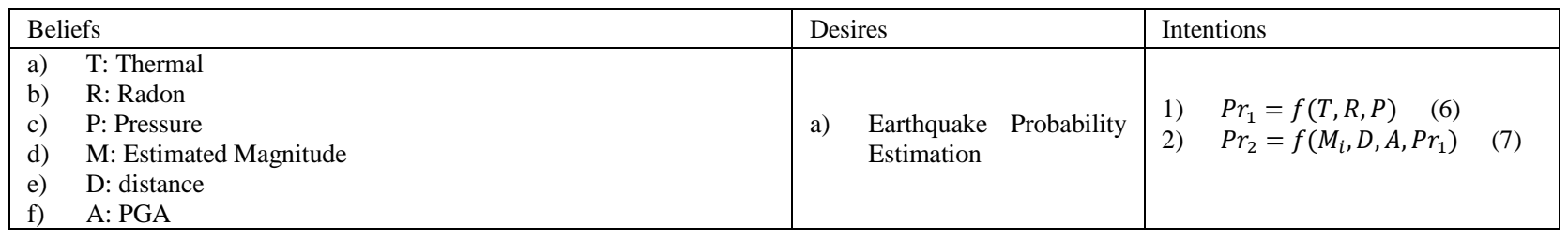

Table 3. Attenuation Estimation Agent

\begin{tabular}{|c|c|c|}
\hline Beliefs & Desires & Intentions \\
\hline $\begin{array}{ll}\text { a) } & \text { Location }(X, Y, Z) \\
\text { b) } & \text { Time And Date } \\
\text { c) } & \mathrm{d} \text { : distance } \\
\text { d) } & \mathrm{A}_{0}: \text { constants } \\
\text { e) } & \mathrm{n} \text { : constants } \\
\text { f) } & \mathrm{k} \text { : constants }\end{array}$ & a) Attenuation(Strength) & 1) $\quad A=A_{0} d^{n} e^{-k r}$ \\
\hline
\end{tabular}

A: the peak ground acceleration (PGA)

Table 4. Earthquake Time Estimation Agent

\begin{tabular}{|c|c|c|}
\hline Beliefs & Desires & Intentions \\
\hline $\begin{array}{ll}\text { a) } & \text { Temperature } \\
\text { b) } & \text { e: correction factor } \\
\text { c) } & \text { d: distance } \\
\text { d) } & \text { S: structural factor }\end{array}$ & Remaining Time & $\begin{array}{l}\text { 1) } \quad T=d /(8 * e) \quad(9) \\
\text { 2) } \quad e=f(\text { Temperature }, S) \quad(10)\end{array}$ \\
\hline
\end{tabular}

Table 5. Epicenter Location Estimation Agent

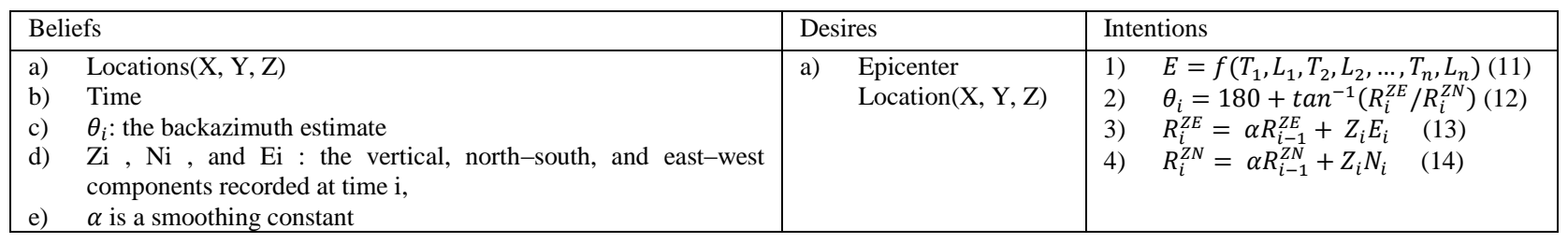

These precursors are temperature anomaly, pressure anomaly, and change in radon, electromagnetic change and geological movements monitored by GPS. For each situation based on the input information, an appropriate action is defined. Sensors' information will be used in the database. This information is used for pattern recognition. Data mining technique is used for discovering hidden pattern for earthquake prediction in terms of precursors. In accordance with the agents' inputs, rule extraction based on the inputs and historical data and the knowledge base, contingency actions will be performed. These actions are codified into two groups, which are early warning and automated actions. Each of these groups consists of different levels based on the earthquake magnitude. Intelligent hardware agents are capable of rapid data preprocessing, data processing and data fusion once they receive data and this advantage make the system capable of early earthquake determination and consequently real-time alarm or action will be performed. Promising results are considered, as the each fraction of time is vital in this matter. Using this system for disabling urban gas distribution network and electrical network can restrain any subsequent damages like firing and explosions. Disabling trains and subways once the earthquake occurs can be another application of this system. The system also can release early warning alarm in public areas like schools, hospitals or public offices, regarding the estimated earthquake magnitude. This early warning alarm makes some chances for people to exit or move to a safer place which will decrease the casualty of earthquake. For practical system evaluation, the research team embarks on developing the earthquake simulator system. The system was developed in C\# and by applying SQL Server 2005 for data capture and keeping. The system simulated earthquakes with the magnitude of 1 to 10 Richter considering 36 seismograph stations and data recording for these stations. The stations receive various data relating to earthquake and monitor them. If an earthquake occurs, which is generated randomly, the first station receiving the primary waves calculated the parameter related to the location, time and magnitude of upcoming earthquake and register the records into database. Then it notifies other stations and based on the calculated magnitude, intensity and depth of earthquake predefined strategies, warning or automated actions will be performed. In order to boost the system processing speed, multithreading of functions in C\# was utilized. This characteristic makes it possible to perform multi process in same time and in parallel manner. The ability to perform multi process in same time and in parallel manner is similar to intelligent hardware agents. The summon of agent and agent interactions is possible in the simulated system. Regarding the complexity of the computational processes 
relating to earthquake precursors, agent parallel processing leads to calculation speed enhancement and the final result of whole process will be available faster. Therefore, we tried to define the functions autonomously being process in parallel manner, according to the proposed model. In the table 6 the results of software agents implementation on two systems with Windows $\mathrm{XP} \mathrm{Sp} 3$ and Windows 7 and hardware agent implementation on two sample system from Xilinx are presented. The third and fourth rows of table 6 are based on Naji [27] which compare the run time of software and hardware agents. As it is demonstrated, application of hardware agents can increase the speed of run time significantly which is vital in the case of earthquake early warning system. In terms of contributions presented in this research, we have speed augment in two stages. First by application of software agent using parallel processing rather than serial processing and then, application of hardware agent instead of software agent. The system was tested into phase, structured and functional implementation, and multi agent and parallel processing implementation. The system run time for similar process was recorded for two phases and the time of multi agent and parallel processing implementation is 2.7 times less than consecutive structured and functional implementation. In terms of the investigation of Naji [27] research the hardware multi agent systems run time is 24 to 32 times less than software multi agent systems. So by applying hardware multi agent for rapid earthquake alarm system and real-time automated action, the system will be capable of processing 70 to 90 times faster and consequently faster warning or action is performed while as the earthquake occurs the any fraction of time is vital.

Table 6. Results

\begin{tabular}{|c|c|c|c|}
\hline Speed increase & Run time (MicroSec) & OS & Hardware \\
\hline---- & 1562 & Windows XP SP3 & Cpu 2.2 Core2Due 3MB L2 32bit,2GB DDR2 Ram \\
\hline 1.3 times more & 1228 & Windows 7 & Cpu 2.8 Core2Due 6MB L2 32bit ,4GB DDR2 Ram \\
\hline 24 times more & 65 & \multicolumn{2}{|c|}{ Xilinx-VirtexII 2v500fg456- 32bit } \\
\hline 3 times more & 48 & \multicolumn{2}{|c|}{ Xilinx-VirtexII 2v10000ff1517- 32bit } \\
\hline
\end{tabular}

\section{CONCLUSION}

The earthquakes with the magnitude of 5.5 Richter or more are the most destroyer natural disaster for people lives and properties. During 1900-1976 more than 2.7 million people have died for sake of earthquakes. During the same time 1.8 million people have died for sake of other natural disasters except earthquakes. The statistics shows that the earthquake is the most destroyer natural disaster for people lives and properties. The matter that makes the earthquake most dangerous disaster is its occurrence, which is not predictable and surprise people. Despite scientist studying, no definite and scientific method is discovered for earthquake prediction. The importance of speed enhancement is so much as any fraction of time is vital before and once the earthquake occurs. The time between the primary waves and damaging waves is considered as vital chance for warning or performing contingency actions and it can impact on saving the people lives. Parallel processing and cooperation of hardware multi agent systems is so helpful for real-time processing of earthquake precursors' information and adopting apt strategy for warning and automated action. In this paper we tried to develop and test a system for early warning and real-time action once the earthquake occurs. Data collected by the stations will be used for developing knowledge base and further earthquake prediction.

\section{REFERENCES}

[1] Yeats, R. S. and A. M. Robert .2001. Geology of Earthquakes. Encyclopedia of Physical Science and Technology. New York, Academic Press: 649-661.

[2] U.S. Geological Survey .2010. Faqs - Measuring Earthquakes. Retrieved 2010/02/18, 2010, from
http://earthquake.usgs.gov/learn/faq/?categoryID=2.

[3] Faccioli, E. 1983. Measures of Strong Ground Motion Derived from a Stochastic Source Model. International Journal of Soil Dynamics and Earthquake Engineering 2(3): 135-149.

[4] Papadimitriou, E. E. 1994. Long-Term Earthquake Prediction of Large Shallow Mainshocks Along the Tonga-Kermadec-New Zealand Seismic Zone Based on a Time- and Magnitude-Predictable Model. Tectonophysics 235(4): 347-360.

[5] Shalimov, S. and M. Gokhberg .1998. LithosphereIonosphere Coupling Mechanism and Its Application to the Earthquake in Iran on June 20, 1990. A Review of Ionospheric Measurements and Basic Assumptions. Physics of the Earth and Planetary Interiors 105(3-4): 211-218.

[6] Saygili, G. and E. M. Rathje .2009. Probabilistically Based Seismic Landslide Hazard Maps: An Application in Southern California. Engineering Geology 109(3-4): 183-194.

[7] Meng, J. 2007. Earthquake Ground Motion Simulation with Frequency-Dependent Soil Properties. Soil Dynamics and Earthquake Engineering 27(3): 234-241.

[8] Utkin, V. I. and A. K. Yurkov. 2010.Radon as a Tracer of Tectonic Movements. Russian Geology and Geophysics 51(2): 220-227.

[9] KülahcI, F., M. Incez, M. Dogru, E. Aksoy and O. Baykara .2009. Artificial Neural Network Model for Earthquake Prediction with Radon Monitoring. Applied Radiation and Isotopes 67(1): 212-219.

[10] Uyeda, S., T. Nagao and M. Kamogawa .2009. ShortTerm Earthquake Prediction: Current Status of SeismoElectromagnetics. Tectonophysics 470(3-4): 205-213.

[11] Novikova O and R. I 1999. Performance of the Earthquake Prediction Algorithm Cn in 22 Regions of the World. Physics of the Earth and Planetary Interiors 111: 207-213.

[12] Vorobieva, I. A. 1999. Prediction of a Subsequent Large Earthquake. Physics of the Earth and Planetary Interiors 
111(3-4): 197-206.

[13] Murru, M., R. Console and G. Falcone. (2009). Real Time Earthquake Forecasting in Italy. Tectonophysics 470(3-4): 214-223.

[14] Pulinets, S. A. 2006. Space Technologies for Short-Term Earthquake Warning. Advances in Space Research 37(4): 643-652.

[15] Talebian, M.,Latifi, K., Amini, B., Fereydoni, A., Anbaran, H.and Nemati, M., (2007). Investigating the records of electromagnetic precursor station of Tehran for a two-year period. The first conference of earthquake precursor. 160-166.

[16] Resaneh, G and Hajbabaee, N. (2007). Introducing some weather precursor and analyzing the trend of their variations prior to earthquake (The case of Bam earthquake). The first conference of earthquake precursor. 102-109.

[17] Ondoh, T. 2009. Investigation of Precursory Phenomena in the Ionosphere, Atmosphere and Groundwater before Large Earthquakes of $\mathrm{M}>6.5$. Advances in Space Research 43(2): 214-223.

[18] Nanjo, K. Z., J. R. Holliday, C. c. Chen, J. B. Rundle and D. L. Turcotte .2006. Application of a Modified Pattern Informatics Method to Forecasting the Locations of Future Large Earthquakes in the Central Japan. Tectonophysics 424(3-4): 351-366.

[19] Adeli, H. and A. Panakkat .2009. A Probabilistic Neural Network for Earthquake Magnitude Prediction. Neural Networks 22(7): 1018-1024.

[20] Alcik, H., O. Ozel, Y. M. Wu, N. M. Ozel and M. Erdik . 2010. An Alternative Approach for the Istanbul Earthquake Early Warning System. Soil Dynamics and Earthquake Engineering. In Press, Corrected Proof.

[21] Manjunatha, K.C., Mohana, H.S. and Vijaya, P.A.2015. Implementation of computer vision based industrial fire safety automation by using neuro-fuzzy algorithm. I.J. nformation technology and computer science 04:14-27.

[22] Hepsiba, M. and Justus, S. 2016. A review on the knowledge representation models and its implementations. I.J. Information technology and computer science 10:7281.

[23] Hazra, T., Kumar C. and Nene, J. 2017 Strategies for searching targets using mobile sensors in defense scenarios. I.J. Information technology and computer science 5:61-70.

[24] Abedinzadeh, S. and Sadaoui, S. 2013. A Rough Setsbased Agent Trust Management Framework. I.J. Intelligent systems and applications 04: 1-19.

[25] Balbo, F. and S. Pinson .2005. Dynamic Modeling of a Disturbance in a Multi-Agent System for Traffic Regulation. Decision Support Systems 41(1): 131-146.

[26] Chow, H. K. H., K. L. Choy and W. B. Lee. 2007. A Dynamic Logistics Process Knowledge-Based System an Rfid Multi-Agent Approach. Knowledge-Based Systems 20(4): 357-372.

[27] Naji, H. R. 2008. Solving Complex Computational Problems Using Multiagents Implemented in Hardware. Computing in Science \& Engineering 10(5): 54-63.

[28] Naji, H. R., B. E. Wells and L. Etzkorn .2004. Creating an Adaptive Embedded System by Applying Multi Agent Techniques to Reconfigurable Hardware. Future Generation Computer Systems 20(6): 1055-1081.

[29] Doniec, A., R. Mandiau, S. Piechowiak and S. Espié .2008. A Behavioral Multi-Agent Model for Road Traffic Simulation. Engineering Applications of Artificial Intelligence 21(8): 1443-1454.
[30] Naji, H. R. and B. E. Wells .2002. On Incorporating Multi-Agents in Combined Hardware/Software Based Reconfigurable Systems - a General Architectural Framework. System Theory, 2002. Proceedings of the Thirty-Fourth Southeastern Symposium on.

[31] Biswas, P. K. and S. Phoha .2004. A Middleware-Driven Architecture for Information Dissemination in Distributed Sensor Networks. Intelligent Sensors, Sensor Networks and Information Processing Conference Proceedings of the 2004.

[32] Naji, H. R. 2005. Sensor Fusion Using Hardware Agents, an Implementation Example. Industrial Informatics, 2005. INDIN '05. 2005 3rd IEEE International Conference on.

[33] Hsiao, N.-C., Y.-M. Wu, L. Zhao, D.-Y. Chen, W.-T. Huang, K.-H. Kuo, T.-C. Shin and P.-L. Leu.2010 A New Prototype System for Earthquake Early Warning in Taiwan. Soil Dynamics and Earthquake Engineering In Press, Corrected Proof.

[34] Asgary, A., J. K. Levy and N. Mehregan.2007. Estimating Willingness to Pay for a Hypothetical Earthquake Early Warning Systems. Environmental Hazards 7(4): 312-320.

[35] Naji, H. R. 2003. Implementing Data Flow Operations with Multi Hardware Agent Systems. System Theory, 2003. Proceedings of the 35th Southeastern Symposium on.

\section{Authors' Profiles}

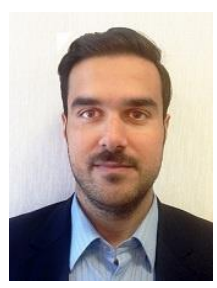

Ahmad Ghodselahi is R\&D consultant in Day bank. He earned his degree of MSc in information management from Tarbiat Modares University and $\mathrm{PhD}$ in management from university of Tehran. His field of research is strategic planning, marketing strategies, machine learning and data mining.

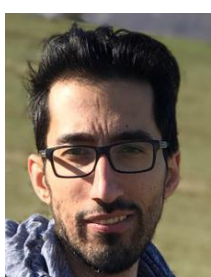

Mostafa Ghodselahi Works at Day Bank as Data analyst. He has MSc in Information Technology Management and BSc in Industrial Management. His Working Interest are Strategic And Operational Planning, Data Mining And Business Intelligence, and Business Development.

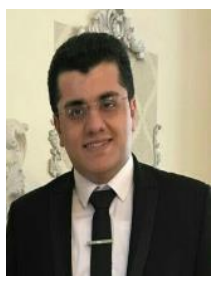

Farid Tondnevis is $\mathrm{PhD}$ Candidate of Finance and has MSc in industrial Engineering (finance sub discipline) and $\mathrm{BSc}$ in Industrial Engineering. His research interests include financial risk management techniques and models based on Business intelligence approach and portfolio optimization (active and passive approaches)

How to cite this paper: Ahmad Ghodselahi, Mostafa Ghodselahi, Farid Tondnevis, "Rapid Earthquake Alarm System and Real-Time Automated Action: Application of 
Multi-Agent Hardware", International Journal of Information Technology and Computer Science(IJITCS), Vol.10, No.2, pp.73-82, 2018. DOI: 10.5815/ijitcs.2018.02.07 